\title{
El espacio arquitectónico de Dom Hans van der Laan \\ Como interpretación contemporánea de connaissance poetique en la arquitectura sacra
}

\author{
Dom Hans van der Laan's architetonic space as a contemporary interpretation of connaissance poetique \\ within sacred architecture
}

Caroline Voet \& Yves Schoonjans

https://doi.org/10.17979/aarc.2011.2.2.5064

«Una iglesia es un espacio arquitectónico sin un propósito especifico. Es simplemente un espacio para estar, para moverse y hablar, una habitación para vivir en el sentido genérico de la palabra: el espacio que necesitamos naturalmente para situarnos en el espacio de la naturaleza y para sentirnos como en casa» ${ }^{1}$.

La arquitectura religiosa occidental del siglo XXI no se define principalmente por códigos litúrgicos, símbolos y tipologías fijas. Ha surgido un cambio hacia una arquitectura que logra su sacralidad por medio de los sentimientos que provoca, y en la cual la espiritualidad se consigue a través de la experiencia física y táctil directa. La espiritualidad, en este sentido, es evocada por la materialidad y la corporalidad del espacio.

La Herz Jesu Kirche de los arquitectos Allmann, Sattler y Wappner, construida en 2000 en Munich, consiste en un volumen rectangular con dos capas diferentes: en el interior hay paneles de madera de diferentes densidades, y en el exterior, una cascara de vidrio con diferentes grados de opacidad. El espacio se define a través de su cascara, con una relación variable con el exterior, una gama de atmósferas y condiciones lumínicas cambiantes.

Esta clase de iglesias contemporáneas no se construye como expresión de las convicciones religiosas personales de un arquitecto. Están construidas como casas, en el sentido de que quieren ser un espacio espiritual comunitario para la reunión y la contemplación. En su libro Thinking Architecture, Peter Zumthor, el arquitecto de la Veldkapel Bruder Klaus, defiende su poética del espacio como una arquitectura que se enfrenta a la forma y a la construcción explícita de esa forma; la belleza de la forma que se fundamenta en el uso sensual de los materiales y en un orden inherentemente adecuado ${ }^{2}$. «La arquitectura posee una relación específicamente corpórea con la vida, expresada a través de la relación entre la persona y la materia» ${ }^{3}$.

Ya en 1948, el arquitecto holandés y monje benedictino Dom Hans van der Laan (1903/91) escribió sobre los fundamentos objetivos de la forma de una iglesia, lejos de la expresión simbólica de una realidad sobrenatural o la personalidad del arquitecto ${ }^{4}$. Definió la iglesia como una casa, un intermedio entre el ser humano y la naturaleza, igual que una cuchara realiza la transición entre el agua y la boca. Al contrario que sus contemporáneos, él trasladó estos objetivos a un proceso de diseño centrado en las cualidades formales, compositivas y materiales. La principal función de la arquitectura era la de expresar su función, hacer legible el espacio para el intelecto a través de los sentidos. Por contraste con los espacios contemporáneos anteriormente descritos, los motivos de Van der Laan surgieron de su trasfondo benedictino, de buscar el equilibrio entre forma y material. 
Fig. 1. El taller de Oosterhout alrededor de 1935; en el centro, Hans van der Laan.

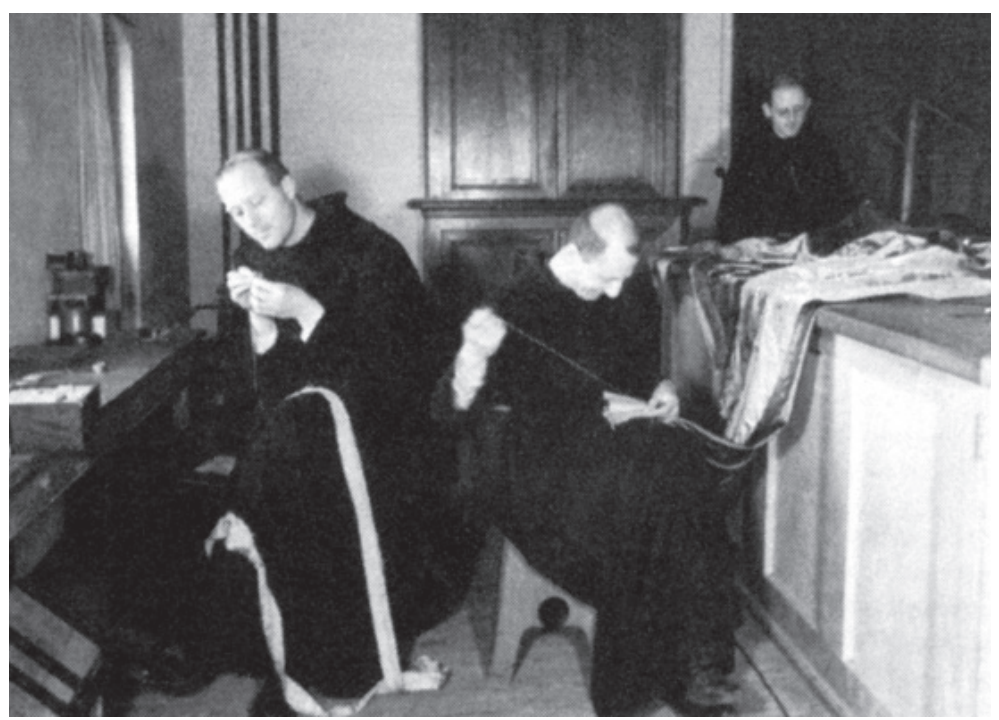

Este artículo revisa cómo Van der Laan se comprometía con el discurso arquitectónico y religioso de su tiempo, para comprender su significado en la actualidad. Así, se pueden revelar los motivos subyacentes esenciales y las interconexiones entre su trasfondo benedictino y la teoría arquitectónica, fundamentando las ideas espaciales inherentemente presentes en la arquitectura religiosa contemporánea ${ }^{5}$.

\section{ORA ET LABORA}

Ya desde la infancia, Hans Van der Laan buscaba los principios fundamentales de la naturaleza y del entorno construido. Le fascinaba cómo se hacían las cosas ${ }^{6}$. Nacido en una familia católica de arquitectos, a una edad precoz conoció los escritos de Dionisio Aeropagita, por ejemplo, un filósofo neoplatónico que introdujo la idea de Imma Summis, según la cual lo más pequeño está en relación cíclica con los más alto y viceversa. El intelecto humano solo puede elevarse a la contemplación de lo espiritual por medio de las cosas materiales que están a su alcance. Antes de entrar en la abadía benedictina de San Pablo en Oosterhout (Holanda), estudió tres años de arquitectura en Delft7. Allí criticó la práctica del diseño caracterizada por la libre interpretación y la copia de los neo-estilos. Él buscaba un proceso de diseño que estuviese más cerca de la realidad del hacer, de la manera en la que «había visto realizar alféizares con su conexión enchufe y agujero, y cómo los enchufes de los alféizares encajaban en los huecos del umbral superior, y se les marcaba con una cruz para que ambas partes quedasen emparejadas y, desde entonces, pertenecían la una a la otra» ${ }^{8}$. Inicialmente influido por sus arquitectos mentores, Granpré Molière y Dom Paul Bellot, Van der Laan encontró sus propias respuestas en la visión neo-tomista del arte, la belleza y la ética de Jacques Maritain?.

Sin embargo, pronto se disociaría del énfasis moral de Maritain sobre la arquitectura y el arte religiosos, volviéndose más hacia su identidad como monje benedictino. Esto demostró ser un aspecto esencial para el posterior desarrollo de su propio pensamiento arquitectónico. Algo inherente a la vida monacal era el equilibrio entre ora \& labora, una contemplación consciente por medio del estudio y el trabajo manual. Ello se reflejaba en un orden general muy estricto en todos los objetos y acciones, desde el horario diario a la ropa, que daba como resultado ritmos específicos en el tiempo, la música y también en el espacio. Van der Laan trabajaba en el taller de costura, donde se centraba en la artesanía por medio del diseño y la confección de vestimentas litúrgicas (Fig. 1). Ya entonces racionalizó este proceso de confección, desvelando los orígenes de los vestidos al analizar los modelos griegos tradicionales. Más adelante, fue responsable de la sacristía, donde antes del fin de la II Guerra Mundial rediseñó todos los objetos litúrgicos de acuerdo con su propio sistema de proporciones, 


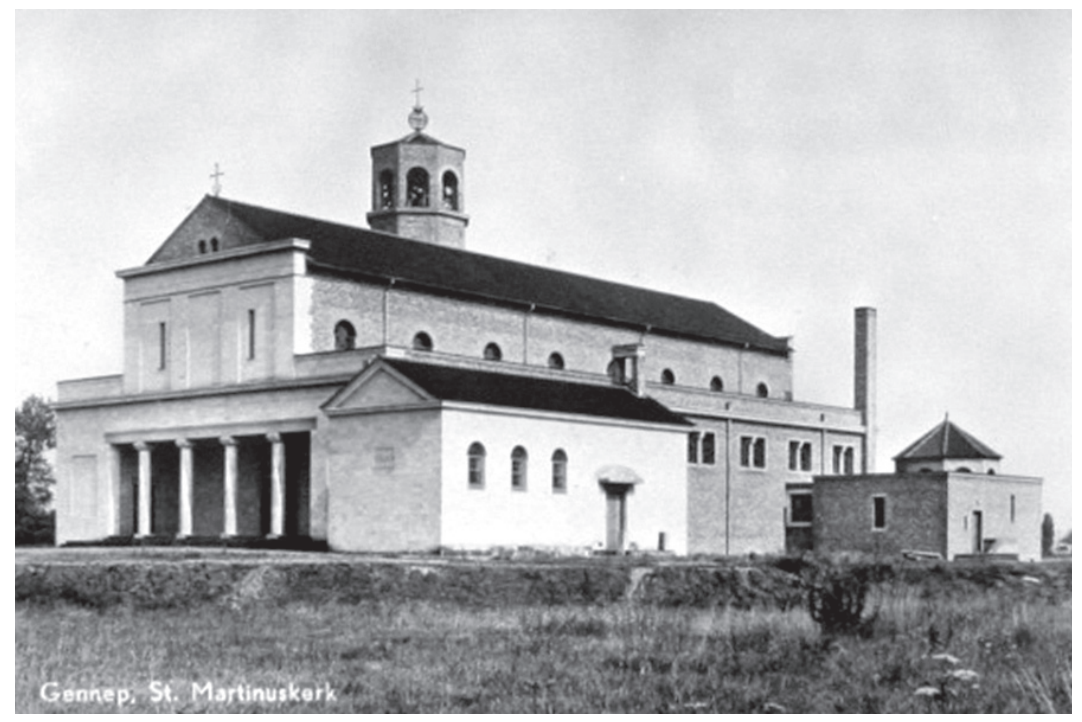

Fig. 2. Nico van der Laan. Iglesia de SintMartinus, Gennep, Países Bajos, 1952/54. que denominaba ratio base o número plástico ${ }^{10}$. Esta ratio (3:4) era diferente de la sección áurea, que estaba explícitamente vinculada a la percepción basada a la capacidad que tienen los seres humanos de distinguir las diferencias de tamaño ${ }^{11}$.

Como parte de la educación benedictina, Van der Laan copiaba fragmentos de los antiguos Padres de la Iglesia y de otros benedictinos, con lo cual trataba de entender cómo se produce la adquisición del conocimiento y la relación entre materia y forma.

\section{PERFIL DE VAN DER LAAN ANTES DE 1957}

Van der Laan aplicó estas ideas a la arquitectura, tratando de traducir ideas profundamente arraigadas de material y forma a la interrelación más concreta entre lo racional y lo sensual, entre lo espiritual y lo material.

Desde su punto de vista, la tarea o función de la arquitectura era la de hacer inteligible el espacio a través de su orden subyacente: lo material que informa a lo espiritual. Una iglesia debía expresar su función. Aunque su primera serie de charlas de 1939 se centraban principalmente en la definición del número plástico $^{12}$, Van der Laan intentó brevemente establecer un argumento informado por sus intuiciones teológicas sobre la idea de connaùtre. Situaba el diseño como el acto de realización entre un ideal racional y la forma material que recibe, colocándolo en el orden material en relación con la problemática de tipo contra aplicación ${ }^{13}$.
Van der Laan y sus alumnos hallaron la expresión arquitectónica fundamental en la basílica cristiana primitiva, proponiéndola como prototipo para la arquitectura religiosa ${ }^{14}$. Entre 1948 y 1956, se construyeron nuevas iglesias basilicales con un escenario general clásico y un uso tradicional de la ornamentación (Fig. 2).

Sin embargo, era este simbolismo tradicional el que criticaba. En una publicación de 1952 explicó: «Como hizo Kropholler al unirse a la postura fundamental de Berlage, Dom Bellot había formulado un sistema teórico cerrado en el cual la técnica de edificación aislada por el goticismo una vez más se dividió en principio de materia y en principio de forma, en que lo último se veía como algo de naturaleza principalmente matemática. Igual que con el gotico, trató de reunir la técnica separada y el principio de la forma pero ahora, asignándole a las matemáticas - el principio de la forma - un contenido necesariamente simbólico» ${ }^{15}$. Simultáneamente, Van der Laan rechazó firmemente la precoz modernidad de Die Neue Sachlichkeit (La Nueva Objetividad), que se centraba en la estandarización y la repetición. En 1957, reaccionó radicalmente contra la arquitectura orgánica de Le Corbusier en Ronchamp, y contra el resultado monumental del concurso de Siracusa, ya que para él, estos eran síntomas del gusto personal del arquitecto ${ }^{16}$.

En principio, sus ideas fueron recibidas con gran interés en los círculos católicos belgas y holandeses, que en el periodo de la posguerra mundial, marcado por la 
Fig. 3. Cripta de la abadía de Sint-Benedictusberg, Mamelis, Vaals, Países Bajos, 1957/61 (hasta 1986 se produjeron reformas de la abadía, como la extensión de la biblioteca).

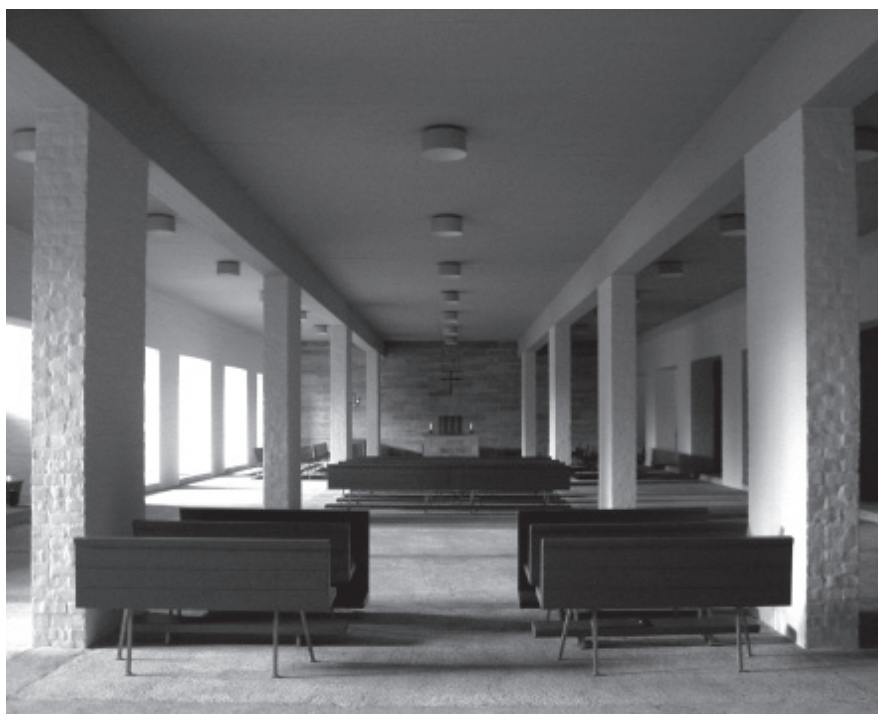

desesperación, buscaban valores firmes. Las charlas en Den Bosch y sus realizaciones eran publicadas regularmente en revistas como Katholiek Bouwblad, L'Art d'Eglise o Schets, y la asesoría de Van der Laan fue muy estimada ${ }^{17}$. Después de 1952, las críticas crecieron desde el lado más progresista, inspirado por las posibilidades de la nueva arquitectura religiosa alemana, suiza y francesa. Las iglesias basilicales, tradicionales y estáticas, no satisfacían las expectativas iniciales ${ }^{18}$. Se consideraba la arquitectura de Van der Laan como demasiado racional y teóricamente rígida, sin ninguna expresión poética o intuición sensible. El objetivo de Van der Laan de recombinar ambos elementos a nivel fundamental no fue alcanzado. Su rechazo radical de la arquitectura de su tiempo tampoco favoreció su postura. Fue injustamente descalificado por tradicionalista o proporcionalista que buscaba la belleza formal a través de las proporciones perfectas, y así desapareció del discurso arquitectónico durante dos décadas. Ni la escena arquitectónica ni el mundo religioso prestaron atención a su nueva aproximación, manifestada a partir de 1957.

\section{EL ESPACIO ARQUITECTÓNICO DE VAN DER LAAN: HACIA UNA FENOMENOLOGÍA DEL ESPACIO}

Van der Laan no sólo fue criticado por la escena arquitectónica general, sino que su propia congregación no apoyó su búsqueda arquitectónica. Su diseño para la iglesia de Oosterhout fue rechazado en $1953^{19}$.
Debido a este impasse, empezó a centrarse en un campo de referencia más amplio, buscando expresiones del espacio más generales y seculares. Analizó las casas romanas, pero también Santa Sofía, y más adelante, los tartanes escoceses o Stonehenge, definiéndolos como patrones legibles y espaciales. Se interesó mucho por la relación entre el interior y el exterior, o por la manera en la cual los espacios más pequeños podían componerse por capas en conglomerados espaciales mayores ${ }^{20}$.

En 1957, se le dio la oportunidad de explorar estas ideas en un nuevo proyecto para la ampliación de la abadía de San Benito en Vaals, Holanda ${ }^{21}$. En el proceso de diseño de la cripta, gradualmente se desplazó desde cualquier forma de ornamentación hacia un espacio más ascético ${ }^{22}$ (Fig. 3, 4 y 5). Los elementos arquitectónicos se definieron como bloques de construcción cúbicos y sobrios y hormigón con mínimos detalles, llamando la atención sobre su ritmo. El espacio siguió estando dispuesto de acuerdo con el número plástico, pero el foco ya no estaba puesto sobre una composición bidimensional de plano y fachada, sino sobre una relación tridimensional entre masa y espacio. Como resultado, el espacio de la cripta se definió como un efecto en capas dinámico, de ritmos variables entre elementos de construcción e intensidades de luz. El uso de acabados sencillos - madera, pintura o revestimiento tosco con escayola en colores grises complementariosrealza las cualidades sensoriales de los materiales, haciendo el espacio extremadamente tangible (Fig. 6, 7, 8 y 9). 


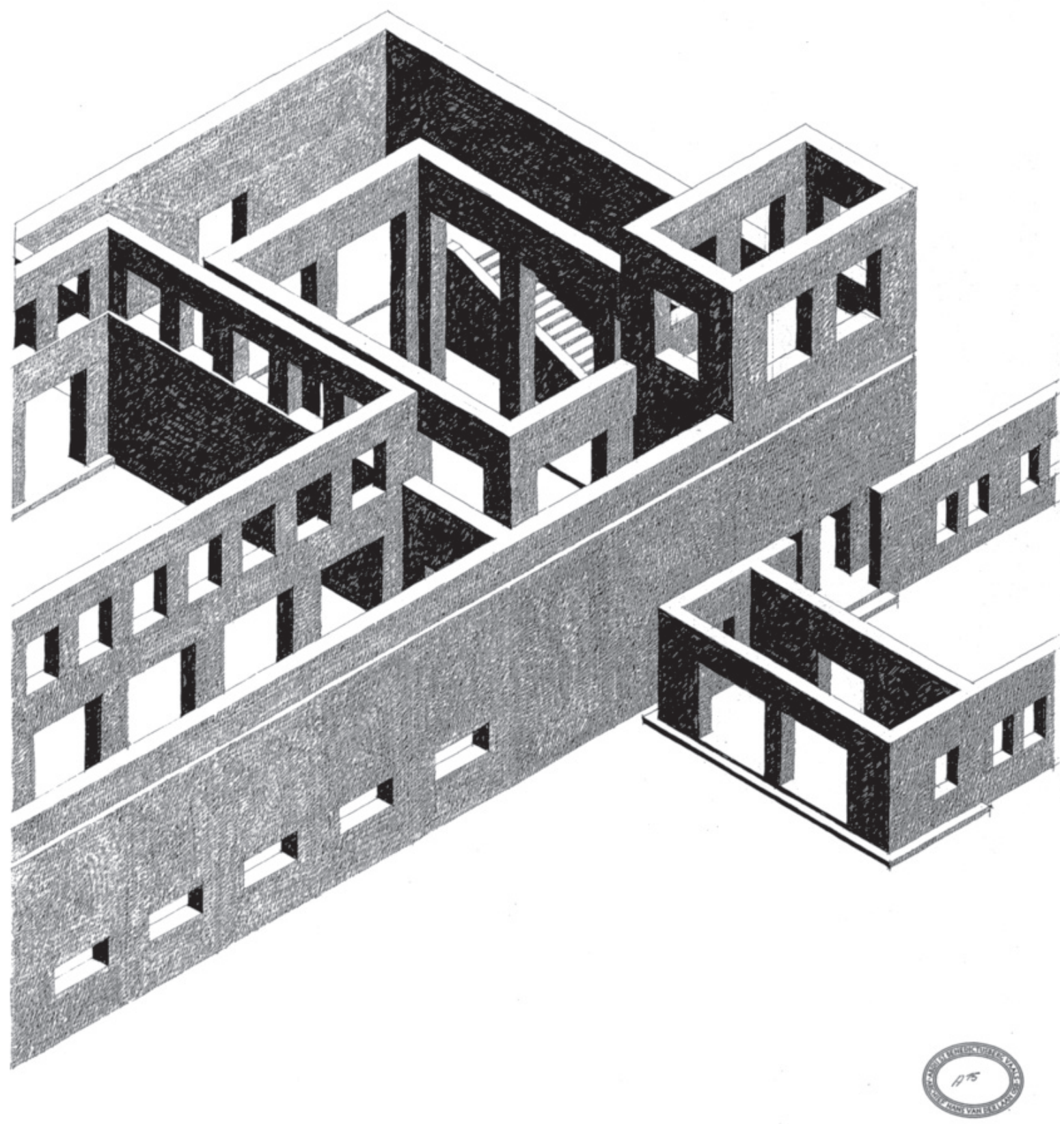


Fig. 4. (En página anterior) Vista isométrica del atrio, la iglesia, la torre y la entrada. Segunda ampliación de la Abadía de Sint-Benedictusberg, Mamelis, Vaals, 1962/68.

Fig. 5. El atrio. Abadía de Sint-Benedictusberg, Mamelis, Vaals.

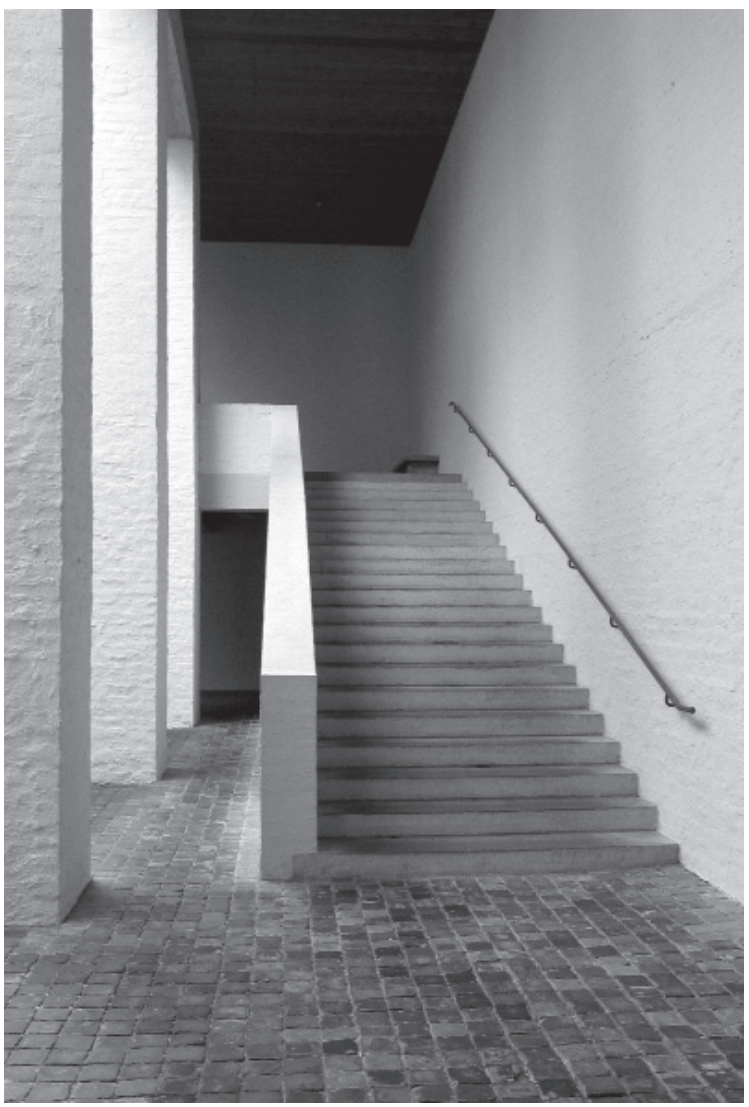

Con el objeto de fundamentar esta arquitectura más sensitiva, Van der Laan sintió la necesidad de utilizar un lenguaje arquitectónico diferente. Una vez más, sus intuiciones ontológicas y teológicas le permitieron alejarse del concepto de una arquitectura prototípica, abriendo el camino hacia un proceso de construcción de formas más fenomenológico. Sus principales intuiciones provenían de la copia de textos de Dom Talma ${ }^{23}$, reinterpretando el conocimiento sobre forma y material a través de los ojos de Tomás de Aquino ${ }^{24}$. En una búsqueda de un proceso objetivo de cognición, puso el énfasis en la connaissance poetique, o conocimiento intuitivo guiado por los sentidos. Fue esta comprensión la que permitió a Van der Laan redefinir los conceptos espaciales que surgían de una relación directa entre el intelecto y los sentidos. Por eso, el énfasis pasó de una idea más platónica de la forma hacia un énfasis más aristotélico sobre la materia, de un ideal racional a una relación mútua entre la inteligencia y la sensibilidad.

A partir de ello, desarrolló modelos que traducían esta relación fenomenológica en ideas espaciales concretas. En 1962, Van der Laan introdujo el concepto de cercanía (nabijheid), involucrando el edificio en la experiencia del espacio ${ }^{25}$. Lo trasladó a la idea concreta de la célula especial, que más tarde llamó cella. Esta unidad espacial básica estaba vinculada a la experiencia de espacio de una persona ${ }^{26}$. Fue éste el campo de referencia subjetiva que definía el límite entre espacio y masa. Un edificio crecía desde la cella, al patio y al entorno (Fig. 10).

\section{EL ESPACIO RELIGIOSO EN EL SIGLO XXI: MATERIA Y FORMA EN LA ARQUITECTURA}

Los conceptos en los que se centraba Van der Laan eran diferentes a las tendencias que seguían sus contemporáneos. No solo diferían de las opuestas aproximaciones vanguardistas y tradicionalistas, si no que la fenomenología de Van der Laan tenía orígenes diferentes a la fenomenología existencial del estructuralismo social mayoritario durante los años 60 y 70 . Su objetivo era el de definir una aproximación fenomenológica objetiva, lejana al subjetivismo27. Como apuntó el eminente crítico belga de arquitectura Geert Bekaert en 1987, «el ser humano sigue siendo el foco central de Van der Laan. No obstante, ese ser es para él el ser humano eterno, un ser humano con necesidades esenciales invariables, sin deseos» ${ }^{28}$. De ello se puede concluir que sus ideas con- 


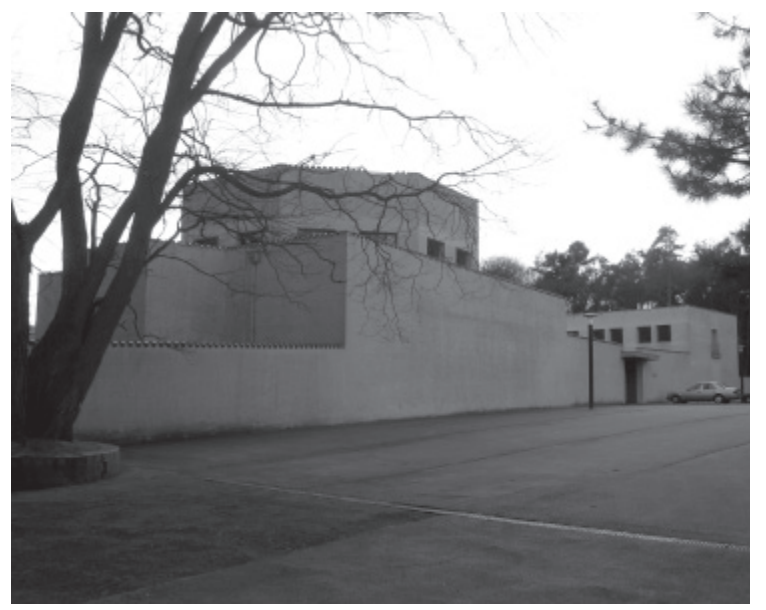

Fig. 6. Abadía de Roosenberg, Waasmunster, Bélgica, 1972/75.

Fig. 8. Vista desde la sala hacia el campanario. Abadía de Roosenberg.

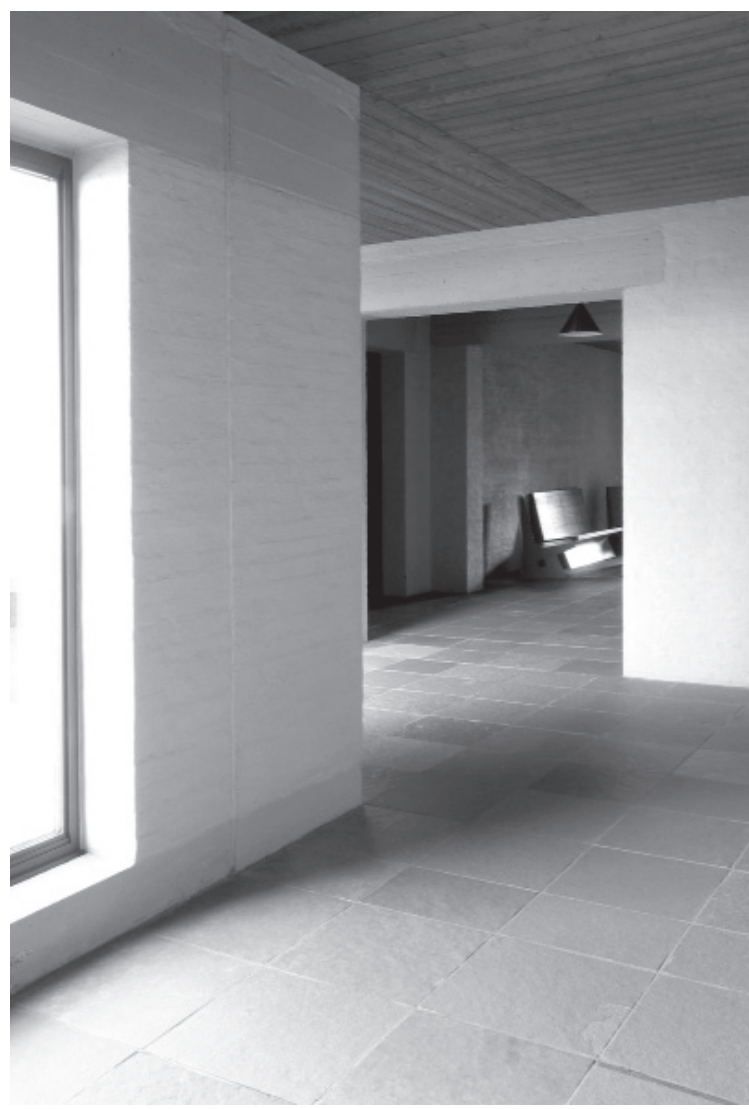

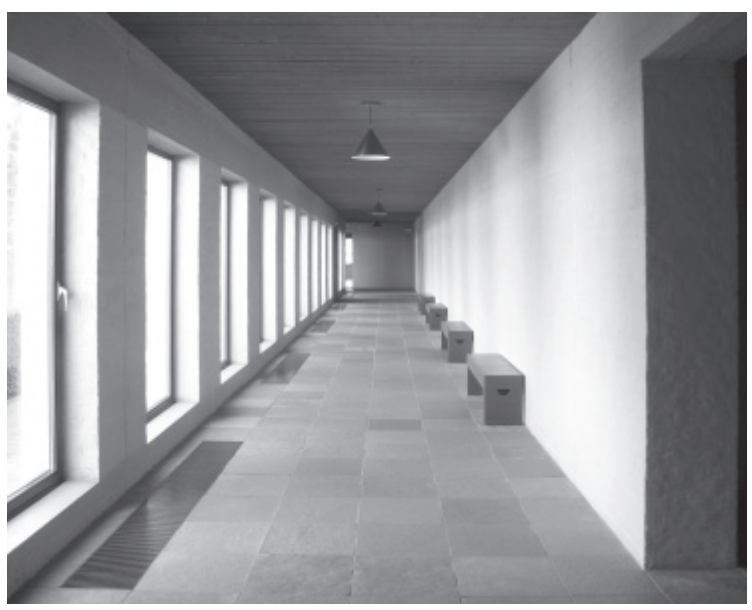

Fig. 7. Sala del convento. Abadía de Roosenberg.

Fig. 9. Escalera hacia las celdas. Abadía de Roosenberg.

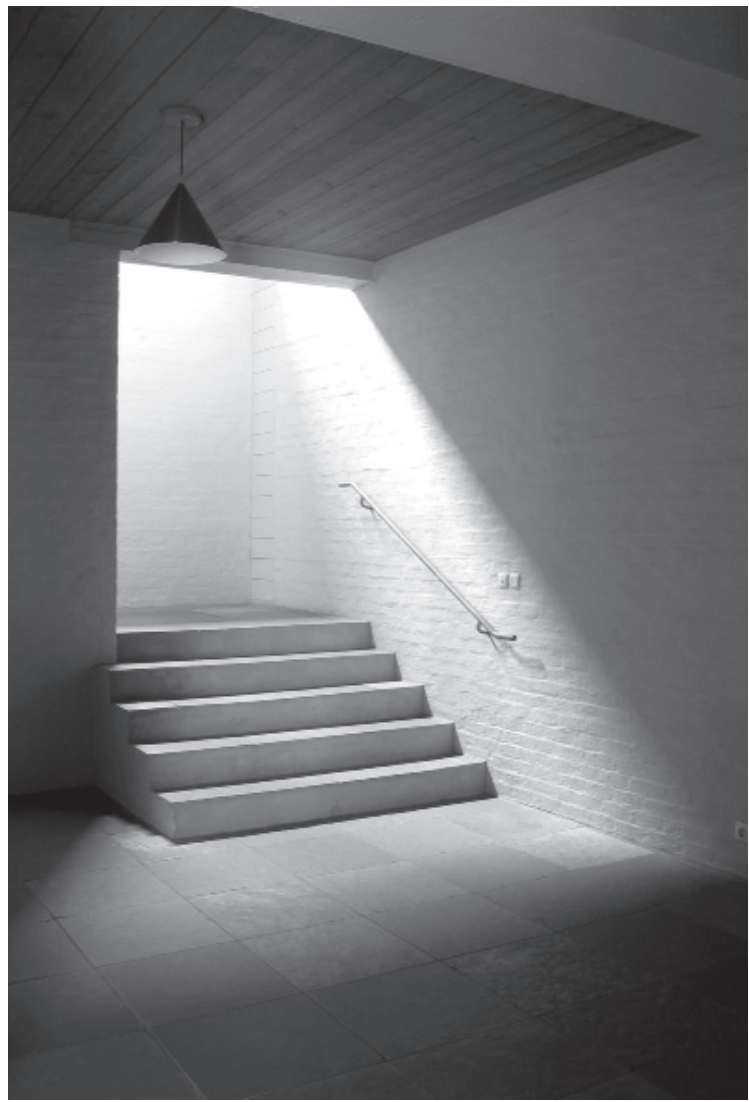


cuerdan más directamente con las teorías espaciales de finales del siglo XIX: la fenomenología del espacio de Wölfflin y la reflexión de Semper sobre la superficie y la ornamentación a través del vestido. Estas teorías espaciales se están releyendo recientemente para formular un fundamento para la arquitectura de Adolf Loos y, a partir de ahí, de Herzog \& de Meuron ${ }^{29}$. La aproximación de Van der Laan concuerda bien con este trasfondo. Ya en 1950, vinculó sus ideas sobre la vestimenta con las de la arquitectura por medio de la idea aristotélica del habi$t u s^{30}$. Escribió acerca de una arquitectura que definía el espacio como los pliegues y costuras de una prenda. El diseño para la cripta de Vaals cumplía esta expectativa. Esta arquitectura de piel o envoltura no se define por medio de su masa, sino a través de sus cualidades espaciales. Vacía de cualquier simetría estructural, las costuras entre los elementos del edificio definen una matriz especial que vuelve a la vida cuando uno se desplaza por ella. El foco está sobre un campo de tensión que emerge de un compromiso directo de la superficie entre la masa y el vacío, y los límites de la propia experiencia.

Van der Laan tuvo éxito al definir la forma como expresión de la materia, estando la materia intrínsecamente vinculada a la experiencia individual, y a través de ella, al proceso de cognición. Con esta aproximación final, fue más allá de cualquier simbolismo religioso. Introdujo un enfoque formal, pero un enfoque que surgía de la fisicidad o corporeidad del espacio. El énfasis residía en el afecto especial o emocional creado por las cualidades materiales. El espacio arquitectónico de Van der Laan, con su capacidad de incorporar conceptos tales como Imma Summis y connaissance poetique, ofrece un fundamento para la arquitectura religiosa contemporánea, más allá del programa del edificio o de la agenda definida por los arquitectos profanos ${ }^{31}$. Además, también ofrece una base para toda la arquitectura contemporánea, que se centra en la inmersión enfática a través de la materialidad y la proporción. En otras palabras, una arquitectura en búsqueda de una sacralidad inherente ${ }^{32}$.

\section{NOTAS}

(1) Dom Hans van der Laan, «Het vormenspel der liturgie», Brill, Leiden, 1985; pág. 89.

(2) En 2007, el arquitecto Peter Zumthor construyó la Veldkapel Bruder Klaus en Mechernich, Alemania, como un paralelogramo cerrado con hormigón tosco que poseía los trazos negros del encofrado quemado. Una apertura en forma de lágrima difunde la luz desde arriba.

(3) Peter Zumthor, «Does Beauty have a form», versión revisada de la charla "Venustas», dada en el Departamento de Arquitectura del Instituto Federal de Tecnología de Zurich, noviembre de 1998, publicada en
«Thinking Architecture», Lars Müller Publishers, Baden, 2006; pág. 78.

(4) Dom Hans van der Laan, «Brieven uit Oosterhout», Katholiek Bouwblad 16 (1948), pág. 55-56.

(5) Entre las obras más importantes de Dom Hans van der Laan pueden destacarse: «De architectonische ruimte» (1977), «Architectonic Space» (1983), «L'espace architectonique» (1989), «Der architektonische Raum» (1992) y «Lo Spazio Architettonico» (2000). Este último reemplazó al anterior «Het Plastisch Getal» (1960), que se centraba más en el sistema de proporciones.

(6) Cf. Dom Hans van der Laan, «Het liturgisch kader van de abdij van Vaals», texto autobiográfico con ocasión de una entrevista televisiva con Antoine Bodar, el 30 de junio de 1986.

(7) En el verano de 1926, Hans van der Laan interrumpió sus estudios de arquitectura en Delft. Estudió un año de latín y griego en la Schola Carolina de La Haya antes de su inauguración en 12 de septiembre de 1927, bajo la guía del jesuita Karel de Wilde. Su ordenación sacerdotal tuvo lugar el 2 de septiembre de 1934.

(8) Dom Hans van der Laan, «Het liturgisch kader van de abdij van Vaals», cit.; pág. 7.

(9) Granpré Molière (1883-1972) fue el profesor de Van der Laan en Delft. Dio lugar a la Delftse School, el movimiento más importante dentro del tradicionalismo holandés. Dom Bellot (1876-1944) es el arquitecto de la abadía de San Pablo, e introdujo a Van der Laan a la práctica de la arquitectura religiosa y en el uso de su sistema de proporciones. Trabajaba de acuerdo con el concepto de innover selon la tradition.

(10) En 1930, Van der Laan trabajaba en el taller de costura, donde se le nombró responsable el 1 de febrero de 1933. En 1936 se encargó de la sacristía, hasta que en 1968 se trasladó a la abadía benedictina de Saint Benedictusberg en Vaals.

(11) El número plástico, aproximadamente $3: 4$, es la solución a la ecuación $\mathrm{x}^{3}=\mathrm{x}+1$, estableciendo una secuencia de ratios. Puede compararse a la sección áurea $\mathrm{x}^{2}=\mathrm{x}+1$, que se utiliza en la serie de Fibonacci. Le Corbusier usó a Fibonacci para definir sus series azul y roja del sistema Modulor. Van der Laan definió un orden de tamaño, una serie de 8 números de $\mathrm{x}$ a $\mathrm{x}^{7}$. Es decir: 1, 4:3, 7:4, 7:3, 3, 4, 16:3, 7. Sus ratios básicas, 3:4 y $1: 7$, están determinadas por nuestra capacidad normal de percibir diferencias de tamaño. El límite inferior es la menor diferencia percibida entre dos tamaños. El límite superior es el límite exterior en el cual dos tamaños pueden relacionarse y compararse a través de la percepción. Más allá de este orden, difieren demasiado y pertenecen a órdenes de tamaño diferentes.

(12) Las teorías Van der Laan se difundieron especialmente a través del Cursus Kerkelijke Architectuur (Curso de Arquitectura Religiosa) en Den Bosch. Van der Laan enseño a muchas generaciones de arquitectos en Den Bosch hasta 1973. Sus conferencias tuvieron una gran influencia en la arquitectura holandesa religiosa de la posguerra, que generó un estilo denominado Bossche School. Ello dio lugar a la publicación del libro «The Plastic Number» en 1960 .

(13) Dom Hans van der Laan, «Eerste van zes bijeenkomsten bij Jan en Nico van der Laan gedurende de oorlog met studiegenoten uit 1923-1927», en: «Professor Granpré Molière. Eerste uiteenzetting van het plastisch getal», Leiden, 1939. Cortesía de la Abadía Sint Benedictusberg Vaals.

(14) El libro de Howard Crosby Butler, «Early Churches in Syriah between the 4the and the 7th century» (Princeton Press, Nueva York, 1929), fue mencionado por varios de los alumnos de Van der Laan como el principal libro de análisis. Van der Laan y sus colegas y alumnos trataron de analizar las proporciones según el número plástico y lo trasladaron a nuevos diseños.

(15) Dom Hans van der Laan, «Kerkelijke Bouwkunst», en: AAVV, «Het Nieuwe Brabant. Eerste deel: Het Brabantse land», Provinciaal Genootschap van Kunsten en Wetenschappen in Noord-Brabant, Hertogenbosch, 1952; pág. 310.

(16) Dom Hans van der Laan, «Vernieuwing in kerkenbouw te Ronchamp en Syracuse: Architectonische ordonnantie en plastische verhoudingen», De Tijd, 13 de julio de 1957.

(17) Van der Laan dio conferencias en varias escuelas de arte, 

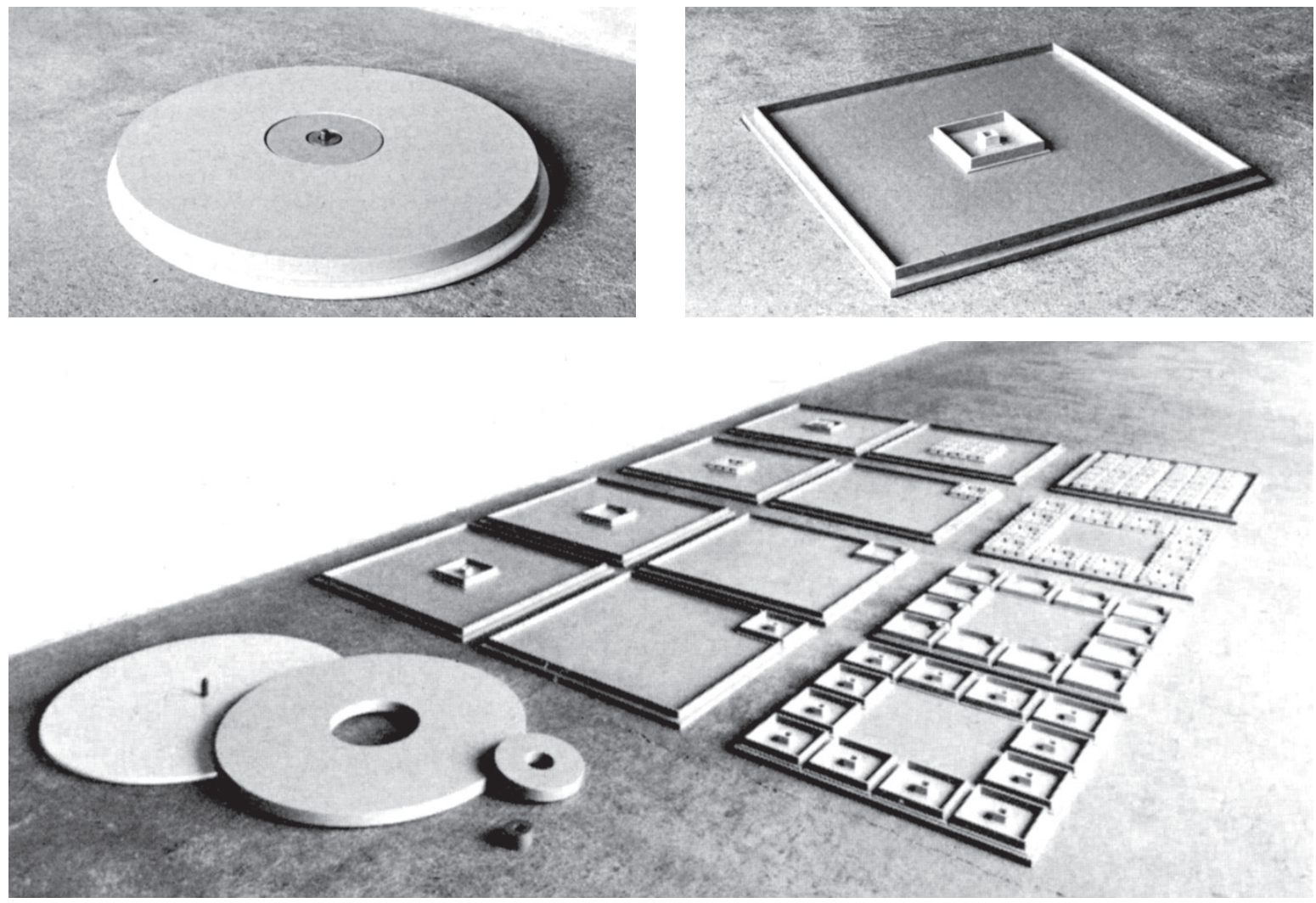

Fig. 10. Maquetas. Experiencia personal del espacio: handelsruimte (espacio de trabajo), loopruimte (espacio para caminar), gezichtsveld (campo visual). Traducción al espacio arquitectónico: las disposiciones de la celda, el claustro y el entorno. 
arquitectura e incluso de música. Asesoró sobre educación artística en SintJoost, Breda, el 13 de septiembre de 1948.

(18) Véase por ejemplo: P. Constantinus (1885-1970), «Terug naar de romantiek», Tijdschrift voor Liturgie 36 (1952), pág. 40-43; Br. Urbain, «Kerkelijke architectuur in Nederland», Schets 8 (1955), pág. 68; o el artículo «Dialogue sur l'architecture de Bois-le-Duc», L'Art d'Eglise 1 (1957), pág. 144.

(19) Los viejos benedictinos como Dom Coebergh, Dom Bergeson o Dom Vermeulen, eran muy críticos con todo el proyecto, especialmente con la iglesia no orientada. En 1953, el proyecto fue asignado al arquitecto Sluymer.

(20) Dom Hans van der Laan, «Over een schotse tartan. Cursus Kerkelijke Architectuur 6», 23 de noviembre de 1968. Una maqueta de Stonehenge, de acuerdo con las proporciones del número plástico, formaba parte del material de estudio en la Bossche School a partir de 1971.

(21) Se le encargaron a Van der Laan una serie de ampliaciones del monasterio de Saint-Benedictus de Mamelis, Vaals, Holanda, en 1957. Realización: 1961, cripta; 1967, iglesia, atrio y cuarto de invitados; 1986, biblioteca y galería. Van der Laan vivió aquí desde 1968 hasta su muerte en 1991. En 1989, como resultado de la realización de la biblioteca, Van der Laan recibió el Premio Architectuurprijs Limburg.

(22) Bajo la influencia de su alumno Jan de Jong (1917-2001). De Jong, que formó parte de la segunda generación de arquitectos de la Bossche School, fue el mejor alumno de Van der Laan.

(23) Dom Talma (1885-1979), matemático y filósofo de Oosterhout.

(24) Este replanteamiento de la connaissance poétique de Platón se produjo bajo el impulso de un cambio general del pensamiento neo-tomista. Los escritos más influyentes fueron los de Klubertanz. Cf. por ejemplo George Klubertanz PSJ, «St. Thomas and the Knowledge of the Singular», The New Scholasticism XXVI (1952), pág. 135-166.

(25) Definió la cercanía como la relación entre masa y espacio, concretamente trasladada al grosor de la pared en relación con el espacio que bordea. De acuerdo con los límites del orden de los tamaños, esta relación era idealmente $1: 7$.

(26) Dom Hans van der Laan, «Vijfde les over de architectonische dispositie», conferencia para el grupo Kerkelijke Architectuur, 3 de septiembre de 1966. Archivo Dom van der Laan.

(27) Aquí Van der Laan se unió parcialmente a la deconstrucción del existencialismo cristiano de Gabriel Marcel (1889-1973) o a los escritos de Albert Dondeyne (1901/85). Ver, por ejemplo: Albert Dondeyne, «Geloof en Wereld», Uitgeverij Patmos, Antwerpen, 1961; y Gabriel Marcel, «Le Mystère de l'otre», París, Aubier, 1951.

(28) Geerd Bekert, «Landschap van kerken, 10 eeuwen bouwen in Vlaanderen», Davidsfonds/Standaard Uitgeverij, Leuven, 1987; pág. 278-285.

(29) Esta línea de pensamiento, que va más allá de las ideas del siglo $\mathrm{XX}$ sobre el funcionalismo y la estructura, vinculando el pensamiento del XIX sobre el espacio y la superficie con ideas contemporáneas de espacio sobre materialidad, tiempo y movimiento, la explica Anne Bordeleau desde el punto de vista fenomenológico en «An Indexical Approach to Architecture», Architecture and Phenomenology, 3 (2008), pág. 79-96.

(30) Grabación de una conversación entre Dom Talma y Dom van der Laan, 7 de julio de 1950; pág. 2. Archivo de Dom van der Laan.

(31) Esta incorporación se explora en el último libro de Van der Laan «Het vormenspel der liturgie» (Brill, Leiden, 1985), traducido al italiano por Kees den Biesen como «La forma: natura, cultura e liturgia nella vita umana» (Sinaí Edizioni, Milán, 2000), y al inglés por Richard Padovan como «The play of forms» (Brill, Leiden, 2005).

(32) «Sus exploraciones del espacio, emancipado de los requisitos funcionales, produce formas que operan utilizando fenómenos religiosos (...) Materialidad extrema en objetos pesados, sólidos, opacos por un lado o materialidad extrema como objetos sueltos, ligeros, lúcidos, esféricos, por el otro: ambos con la intención de una inmersión enfática en lugar de una recepción distanciada, para involucrarse con en lugar de comprender» (Rudolf Stegers, «Sacred Buildings, a Design Manual», Birkhäuser, Basilea, 2008; pág. 33). Stegers se refiere a artistas espaciales cuya obra se atribuye al minimal art, al arte povera o al land art, pero también a los museos cuasi-sacros como el de Peter Märkli (La Congiunta Museum o la Fundación en Giornico, Suiza 1992) o Tadao Ando (museo de la Fundación Langen, cerca de Insel Hombroich, Alemania, 2004). También me refiero a los museos más recientes de Sanaa (New Museum of Contemporary Art, Nueva York, 2007) o Peter Zumthor (museo diocesano Columba, Colonia, Alemania 2007). 